\title{
THE RETURN OF THE SIEGESBURG - 3D-RECONSTRUCTION OF A DISAPPEARED AND FORGOTTEN MONUMENT
}

\author{
S. Deggim ${ }^{\text {a }} *$, T. P. Kersten ${ }^{\text {a }}$, M. Lindstaedt ${ }^{\text {a }}$, N. Hinrichsen ${ }^{b}$

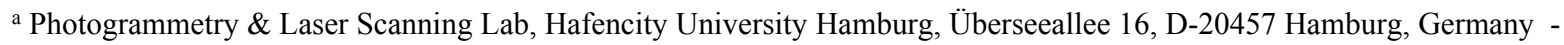 \\ (simon.deggim, thomas.kersten, maren.lindstaedt)@hcu-hamburg.de \\ b Museum Alt-Segeberger Bürgerhaus, Lübecker Straße 15, D-23795 Bad Segeberg, Germany - hinrichsen@vhssegeberg.de
}

\section{Commission II}

KEY WORDS: 3D, cultural heritage, Lumion 3D, modelling, reconstruction, texture mapping, visualisation

\begin{abstract}
:
Many Cultural Heritage $(\mathrm{CH})$ monuments are destroyed in the past and they are often lost forever. If there is no contemporary metric documentation of the historic objects available, the monument and the information about this monument could be disappeared and forgotten forever. The Siegesburg (also known as Segeberg castle) located on the "Kalkberg" (Chalk Mountain) in Bad Segeberg in Northern Germany, is a typical example for such a monument, which was destroyed by Swedish troops at the end of the Thirty Years' War in 1644. This important monument was only documented by a few historic isometric maps, but the castle and even the later castle ruin were totally destructed and demolished over the last centuries and disappeared forever. Furthermore, this significant memorial is even forgotten in many people's mind.

This contribution describes the physical and virtual return of the Siegesburg by 3D reconstruction using historic sources. The laboratory for Photogrammetry \& Laser Scanning of the HafenCity University Hamburg conducted this project in co-operation with the museum Alt-Segeberger Bürgerhaus (Old-Segeberg town house). The process of the 3D reconstruction and visualisation of both the Kalkberg and the castle is presented in this paper.
\end{abstract}

\section{INTRODUCTION}

Cultural Heritage $(\mathrm{CH})$ monuments are significant testimonies of the human past. These memorials are in danger around the world today due to increasing devastation by war, terrorism and vandalism, as well as by creeping weathering. For many $\mathrm{CH}$ objects it is already too late, i.e. they were destroyed in the past and they are probably already forgotten. Examples for the meaningless destruction are among many others the Great Buddha statues from Bamiyan in Afghanistan (Gruen et al. 2002), blown up in March 2001 by the Taliban, the Minaret of the Umayyad Mosque of the UNESCO heritage site of ancient city of Aleppo (Fangi \& Wahbeh 2013), which was destroyed during the current Syrian civil war and the Great temple of Bel in the archaeological momentous site Palmyra in Syria (Wahbeh et al. 2016), one of the most important Syrian heritage monuments, which was destroyed in September 2015 by the so called "Islamic State". These terrible destructions demonstrate clearly that metric documentation of (important) ancient monuments is an essential and very useful reference for a future reconstruction or restoration of those $\mathrm{CH}$ objects. However, a metric documentation is very often not available due to missing appropriate recording techniques and systems in the past. Photography and photogrammetry are used for the documentation of buildings and monuments since the late $19^{\text {th }}$ century (Meydenbauer 1867). Wiedemann et al. (2000) used, for example, photographic glass plates from the Meydenbauer archives for reconstructing historical buildings. Another example for the documentation of historic buildings such as NorthGerman castles by digital photogrammetry is given by Kersten et al. (2004). The advantages of terrestrial laser scanning for the documentation of huge historic buildings such as the Imperial

\footnotetext{
* Corresponding author.
}

Cathedral (Kaiserdom) of Königslutter, Germany, are described in Kersten \& Lindstaedt (2012).

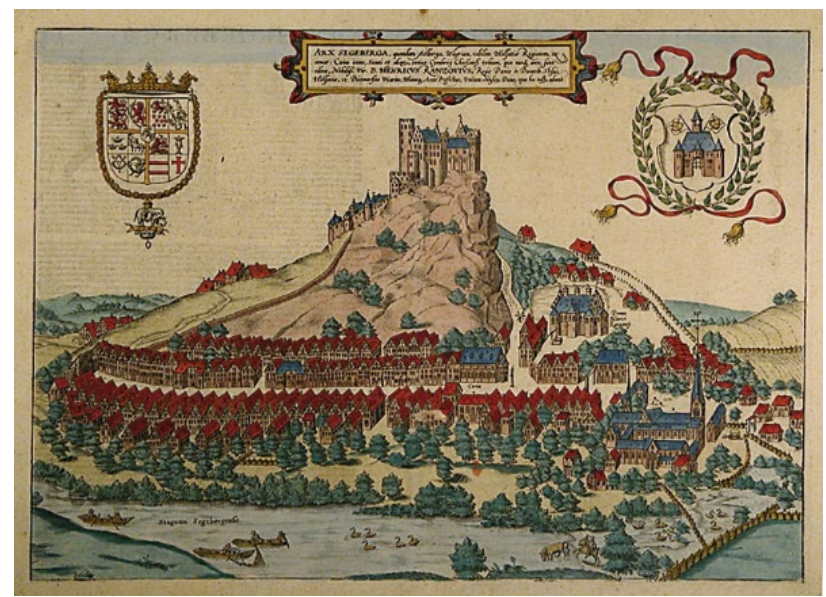

Figure 1. Isometric map of Segeberg including the castle Siegesburg in the year 1588 from Braun-Hogenberg (view from North to South)

However, such modern metric documenting techniques were not available, when the Siegesburg, which is also known as Segeberg castle (Fig. 1), an ancient monument from the Dark Ages and the Early Modern Age (from a time more than 500 years ago) was destroyed in the $17^{\text {th }}$ century and demolished during the following centuries. In this contribution the return of the Siegesburg by $3 \mathrm{D}$ virtual reconstruction is presented. The laboratory for Photogrammetry \& Laser Scanning of the HafenCity University Hamburg carried out this reconstruction in co-operation with the museum Alt-Segeberger Bürgerhaus using 
historic sources such as painting and isometric maps to arouse the important monument. The reconstruction has been conducted in three different phases: a) reconstruction of the Kalkberg, b) reconstruction of the castle in AutoCAD and c) texture mapping and visualisation of the castle with Lumion 3D. A detailed workflow of this project is described in Deggim (2015).

\section{THE HISTORY OF THE SIEGESBURG}

A first castle on the Kalkberg has been built in the first half of the $12^{\text {th }}$ century (1128) by the Danish Duke Knud Lavard, but it was already destroyed in 1130 by the Schauenburg count Adolf I, because he felt the fortress as a threat. The Roman-German Emperor Lothar of Supplinburg (Lothar III) ordered to build a new castle on the Kalkberg after an advice of the missionary Vicelinus in 1134. The castle should serve as a base for the Christianisation at the edge of the border to the Slavic tribes. In the course of various armed conflicts in the following centuries, the castle was several times besieged by enemy troops, sometimes destroyed, and then rebuilt. However, the centrality of the Siegesburg increasingly strengthened its suitability as a centre of political power and as a residence. After the Schauenburg family died out in the $15^{\text {th }}$ century as the owner of the castle, the castle and the County of Holstein passed on 1459 to the Danish King Christian I. However, the castle was 1534 so badly damaged by the devastating city fire that the Danish Governor and bailiff Heinrich Rantzau induced the restoration of the dilapidated Siegesburg as an extensive building complex as it is shown in the engraving by Braun-Hogenberg from 1588 (Fig. 1). After the outbreak of the Thirty Years' War, the castle underwent various occupations. From 1627 until 1629, imperial troops of Wallenstein occupied Segeberg and took the unfortified castle on the Kalkberg without a fight. In retaliation, the open castle had been burned down at the end of the Thirty Years' War in 1644 by the Swedish troops. After further centuries of intensive mining of the Kalkberg only the lower half of the sole castle fountain of Northern Germany with its approximately 42 meters depth left reflects the once-powerful Siegesburg. It was driven into the rock and is today located in a steep reduction wall. Between 1934 and 1937, the Reich Labor Service built the Kalkberg Stadium in the pit created by the gypsum mining. This is an outdoor stage with about 7,800 seats and standing room for 12,000. The Karl May Festival (open-air theatre festival about Karl May's adventure novels about the Wild West) has been held here every year since 1952.

\section{DATA BASIS}

\subsection{Reconstruction of the Kalkberg}

The first step of the project was the reconstruction of the historic Kalkberg. First, the modelling of the Kalkberg was carried out with butter in order to derive just the shape of the mountain without any scale using historic sources such as paintings, isometric maps and descriptions. Secondly, the existing landscape has been modelled by meshing of airborne laser scanning (ALS) data from the national survey of SchleswigHolstein. Fig. 2 (left) illustrates the ALS data as a mesh including the current Kalkberg and the open-air stage of the Karl May Festival in Bad Segeberg. From this DEM, sections with a spacing of $10 \mathrm{~m}$ were generated and plotted in a scale of $1: 330$. These sections were transferred to cardboards, cut out and then fixed upright on a planar platform (Fig. 2 centre) for further modelling with gypsum (Fig. 2 right). Third, the shape of the modelled butter mountain coming out of the fridge was visually transferred to the physical 3D model by manual modelling. The finished physical 3D model of the historic Kalkberg (Fig. 3 left) was photographed with a Nikon D800 for digitisation using dense

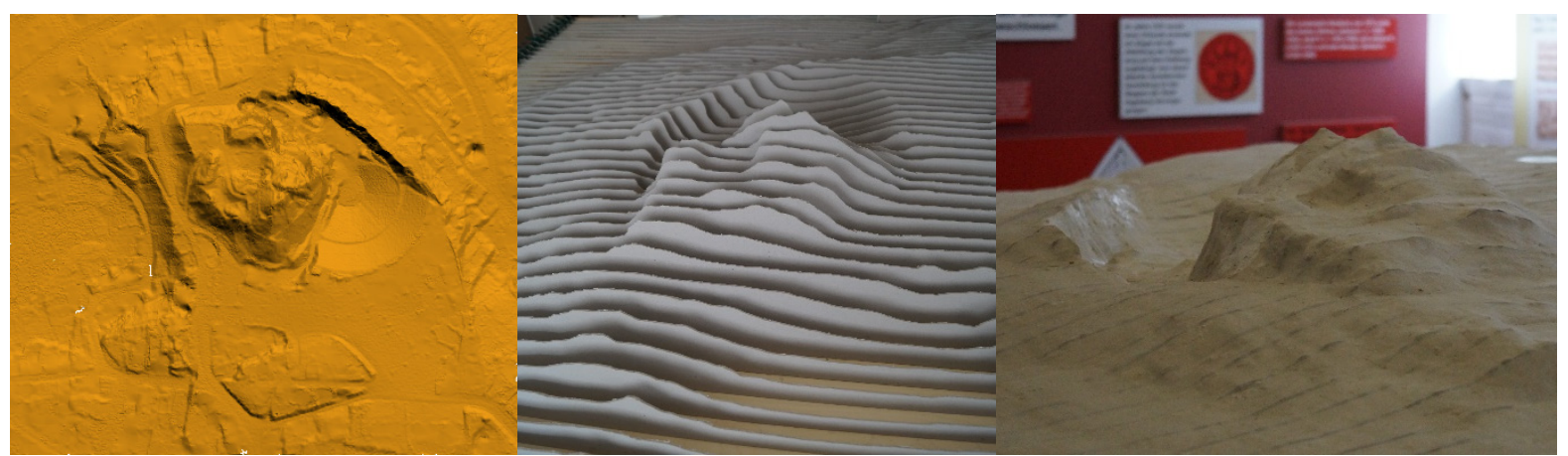

Figure 2. The reconstruction of the Kalkberg from airborne laser scanning data: digital elevation model (original data, left), printed scaled sections of the DEM (centre) and physical 3D model of the today existing Kalkberg (right)

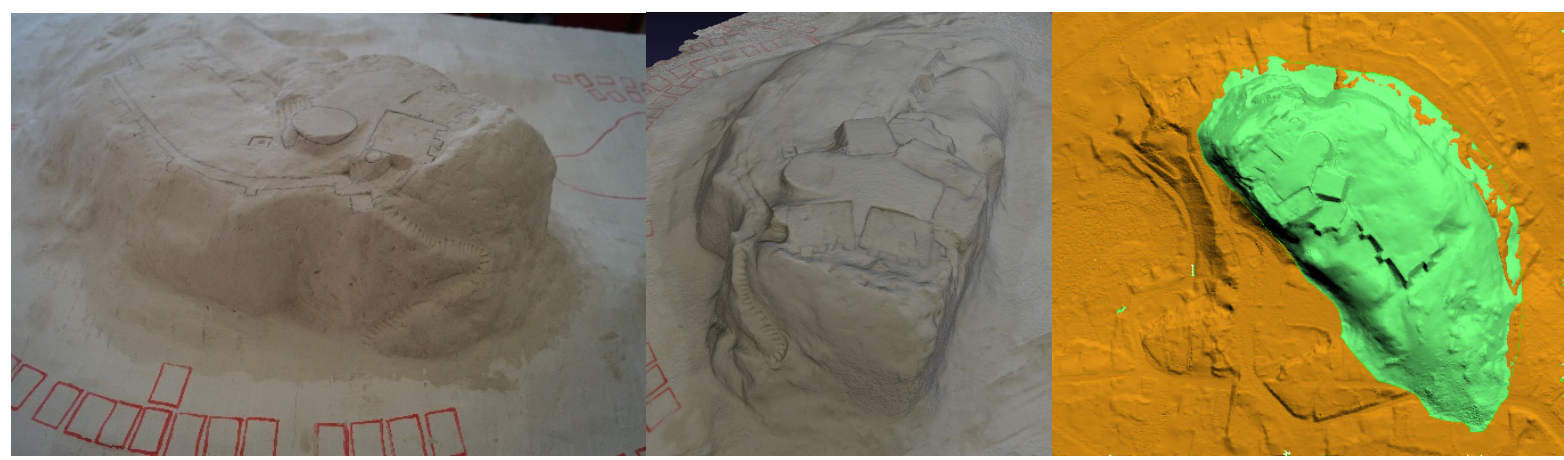

Figure 3. The historic physical 3D model of the Kalkberg (left), the historic digital 3D model from dense image matching (centre) and the combination of two DEMs from both today (orange) and the past (green) (right) 
image matching. The final meshed model is illustrated in Fig. 3 (centre), which was combined with the meshed model from ALS data after scaling (Fig. 3 right). This combined meshed 3D model was the base for the modelling of the Siegesburg.

\subsection{Initial CAD-model of the Siegesburg}

The first virtual 3D model of the Kalkberg and the Siegesburg (Fig. 4 top) was created in Cinema 4D by Dipl.-Ing. Uwe Oswald, lecturer for 3D design at HTK - Academy of Design in Hamburg, some years ago. However, this virtual object includes some small false assumptions about the shape of the castle and it was not very detailed reconstructed. Nevertheless, a second virtual model was created and adapted to the reconstructed digital terrain model of the Kalkberg in Cinema 4D using the expertise of a historian (Fig. 4 centre). This was used by a model builder to create a physical castle model on top of the Kalkberg for the museum exhibition (Fig. 4 bottom).

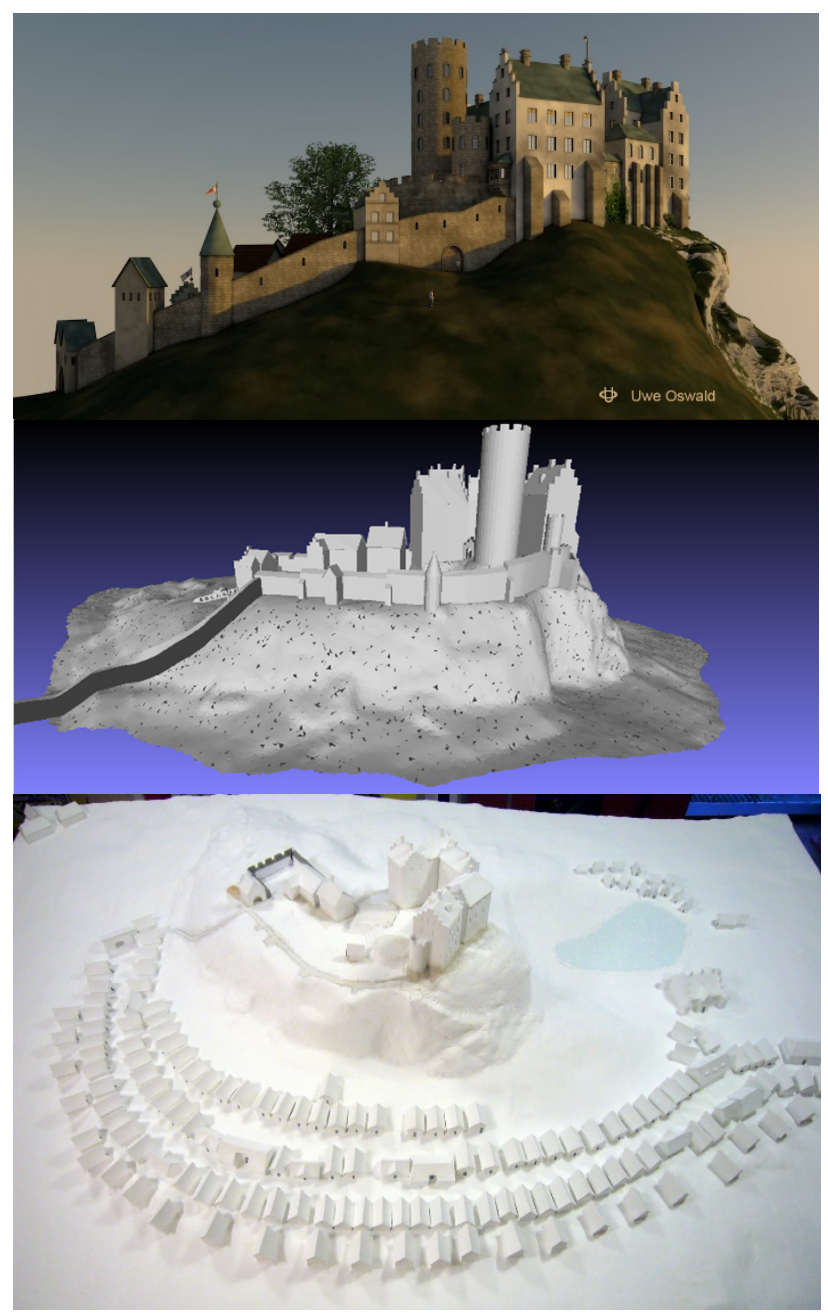

Figure 4. The first virtual 3D model of the Kalkberg and the Siegesburg (top), the second revised version (centre) both created by Dipl.-Ing. Uwe Oswald in Cinema 4D, and the final physical castle model in the museum exhibition (bottom)

\section{MODELLING}

The initial CAD models show the rough position and size of the castle, but it lacks any details which are necessary for the generation of a video sequence allowing the focus on close-up shots from the castle. Thus, the second CAD model (Fig. 4 centre), the physical model in the museum and the available historic illustrations were used as the base for the new model to be constructed. The first step was to research typical elements of Northern European castles in the Early Modern Age and to collect example images. The Siegesburg existed already over 450 years in the year $1600 \mathrm{AD}$ and has often been attacked, partly destroyed, rebuilt, renovated and expanded. Thus, the castle shouldn't have a continuous style but should consist of various architectural elements.

The 3D modelling has been carried out with Autodesk AutoCAD. Due to the size of the castle, it was split in different object parts, constructed individually and was later merged in the visualisation software Lumion 3D. The balance between details and data reduction should be considered, since a high number of polygons results in performance problems of the computer system during the work process (Deggim 2016). This is a very significant factor to be considered, especially if the models are reused for real-time virtual reality applications as used later in a continuing project.

The modelled buildings are based on the image collection. They combine elements from various sources or are based on single images. The shape of each building, given by the initial CAD model, was the starting point for the construction and correction of each object to be modelled. Afterwards, doors, windows, roofs and other details such as a stepped gable or timber framework were added to the building models (Fig. 5 and Fig. 6 top).

To increase the degree of reality, the former use of each building was taken into account. Tower platforms and the defence galleries are reachable via ladders or staircases or they can be accessed from adjacent buildings. Walls without a defence gallery were modelled with arrow slits and machicolations were placed at reasonable locations. The former use of each individual building of the castle is not known in general. However, a typical storehouse scene with a crane was added to the main castle to make the scene lively. For additional variety, small objects like chests, buckets, fences, boxes, torches, tables, benches, cups, weapons, wheels and many other small constructions such as a wooden shelter and a cart were modelled and placed in the scene (Fig. 12 bottom). In total, 21 buildings and 31 scenery objects were modelled and later integrated into the castle scenery.
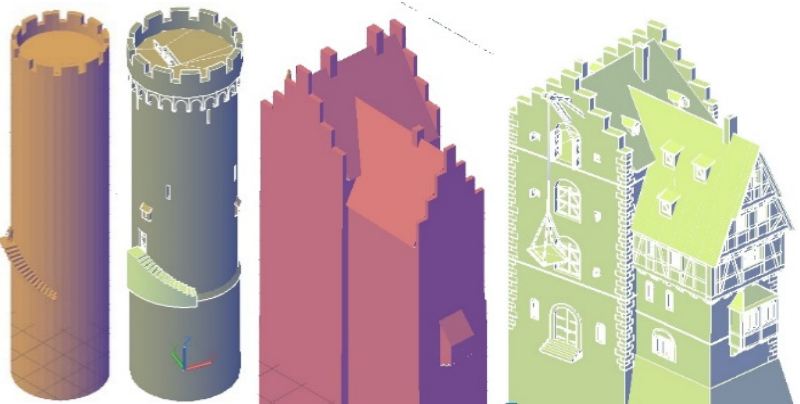

Figure 5. Comparison between initial and final model for the keep (left) and a building at the main castle (right) 


\section{VISUALISATION}

\subsection{Software}

The software package "Lumion 3D" is a visualisation software. Its main target audience are architects and designers. It comes with a material library, foliage items, landscape tools and a highspeed renderer. Compared to established software packages such as 3ds Max, Cinema 4D and many others, it has only minor texture settings and a lack of export options. It is, on the other hand, an easy-to-learn software with a fast workflow and a high number of video and graphic settings. This software was used for texture mapping and all following processing steps such as environment, animations and video production for this project.

\subsection{Texture Mapping}

The material library of Lumion mainly consists of modern architectural textures. Consequently, the textures had to be edited in several ways to fit the old, rough appearance of a postmedieval castle: A) upscaling of most of the textures, especially the ones including stones, B) creating and integrating normal maps to provide reliefs, which supply an overall more realistic look, especially when light sources (e.g. sun) are included in the scene and C) colour correction. Fig. 6 shows the non-textured (top right) and textured (bottom) models of the same building. Further aging process of the objects could be achieved by placing small fauna objects on and at the bottom of a wall, e.g. stones and ivy (Fig. 7).
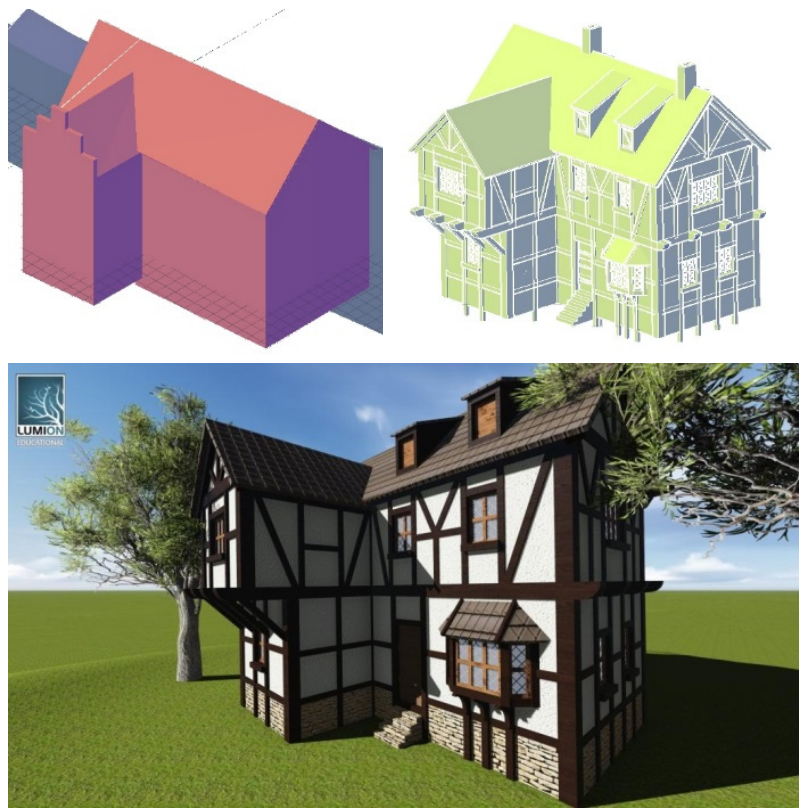

Figure 6. Development of a building in the outer ward: Initial CAD model (top left), detailed model (top right), textured model in Lumion 3D (bottom)

\subsection{Environment}

Landscape: The landscape underneath and around the castle was modelled with the Lumion landscape tools using the 3D reconstruction of the Kalkberg as a basis. Steep parts were mapped with rock textures, while shallow parts were designed as a combination between grass and dirt (Fig. 7). An additional 3D effect was applied to the grass parts, showing individual blades of grass when the camera moves closer to the object.
The surrounding landscape was modelled afterwards based on both todays and historic appearance of the area. As the past 400 years extensively changed the landscape, only the rough pattern of the present look can be used. The historic sources, on the other hand, are known to be inaccurate at some points, e.g. the distribution of hills around the village Segeberg. The shape and position of both lakes near the castle were derived from aerial photographs. The environment around the urban area was modelled with typical agricultural elements, such as farm and grazing land with fences between them. Small forests were added where they are shown on historic sources. Over 6000 trees and plants were placed in the whole scenery. To block the visual axis in the distance, a slight fog was added, not only providing a realistic feeling of distance but also limiting the area, which had to be filled with landscape elements and 3D objects. Fig 8 (top) shows the whole scenery of the castle and its environment from an aerial perspective.

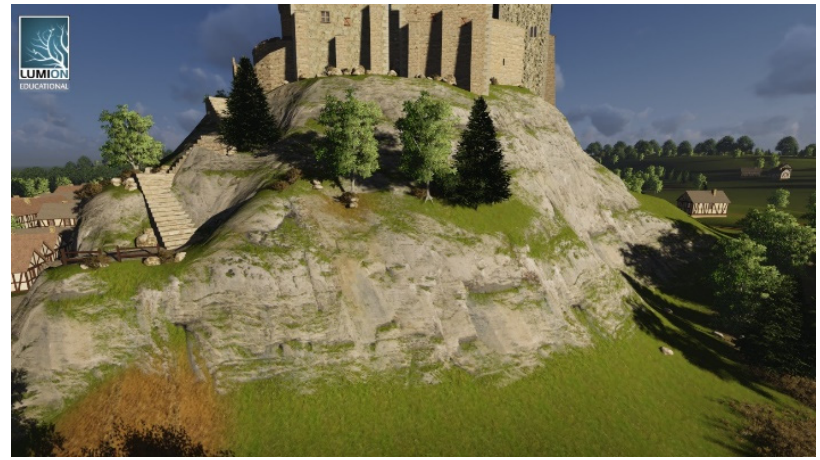

Figure 7. Landscape with rock, grass and trees on the west side
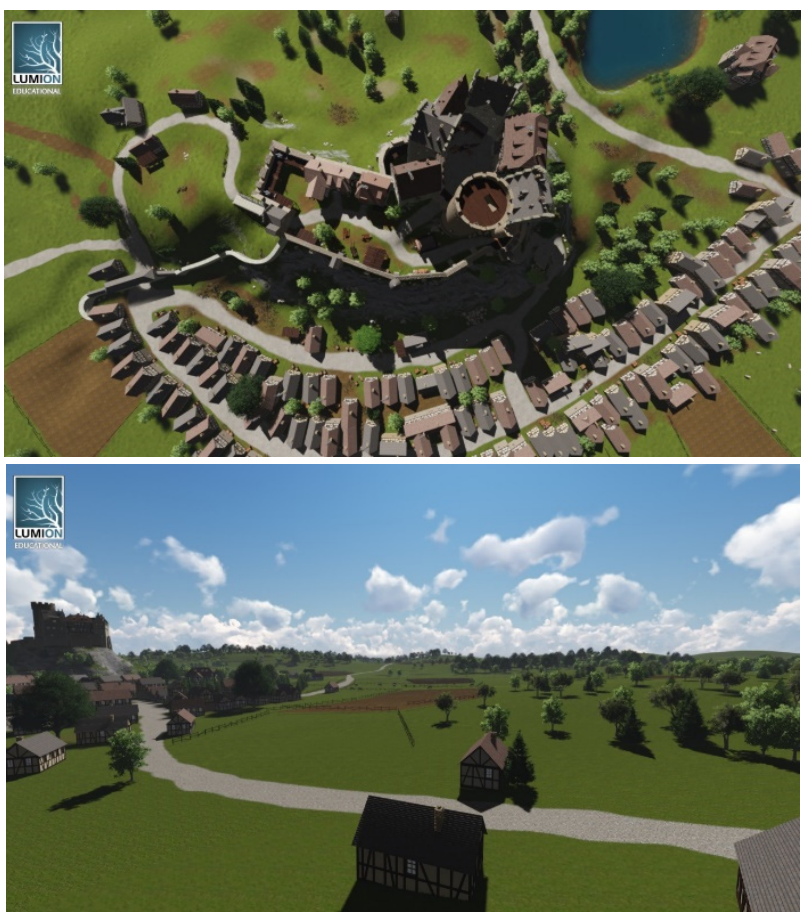

Figure 8. Top view (top) and side view (bottom) of the scene

Urban area: The village of Segeberg (the "Bad" (bath) hasn't been added until the end of the $19^{\text {th }}$ century) itself consisted of approximately a hundred buildings at that time, which were located mainly at the north side of the Kalkberg along the main road from east to west (Lübecker Straße), following the curvature of the terrain. The positions of the buildings are shown in high 
detail on the isometric map of Braun-Hogenberg (Fig. 1). This source was used for the placement of all buildings for the physical model. The resulting derived ground plan was the basis for the creation of the digital model (Fig. 9). Although the focus of this project was on the castle, the surrounding area should nevertheless be historically correct and provide a consistent impression of the background scenery. To facilitate the workload for this reconstruction part, only one building was modelled, having four slightly different sides, which allows for many different appearances due to rotation and combination of two or more copies of the same model. Furthermore, the model was imported twice into the object library using two different textures to allow for a higher variety. Additionally, some of the smaller castle buildings were reused as city buildings.

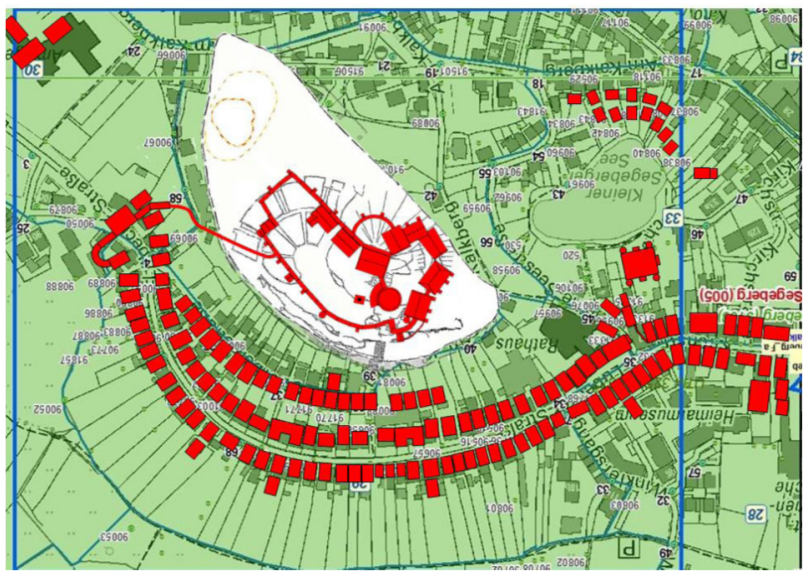

Figure 9. Map of the present city (green) with the state of 1600 as overlay (red)

\section{VIDEO SEQUENCES}

\subsection{Video}

Depending on the potential target group, there are several possibilities to generate a video sequence. The camera path, use of special effects, lighting, cutting and choice of background music may influence both the atmosphere and the message of the video. The aim of this project was a trailer-like sequence, which could be used both for advertisement of the Siegesburg as well as for information purposes in a museum context. The following concepts and effects were used to create the video using the software Lumion.

Camera: To capture the Siegesburg both as a whole in the context of the urban surrounding as well as the details inside the castle, a carefully planned camera path was essential. During the whole sequence, the viewer should not become lost, i.e. he should always be aware of where the current camera position is located in relation to earlier shots. Therefore, several long tracking shots were created and each following shot starts at a position which has already been shown in an earlier shot. Thus, different areas of the castle can be shown without having the location of each area established after each cut.

The video can be partitioned in different sections: A) introduction sequence, with some written information and short cuts with glimpses on some details of the castle to create a sense of excitement, B) overview shot to establish the whole scene with a wide shot, approaching the urban and surrounding area of the castle once, C) first part of the castle tour including the change of the camera angle to eye-level in front of the main gate and keeping the human observer perspective for most of the following sequences. This creates an immersive feeling for the viewer while the camera shows some details in the outer ward, D) tour around the main castle showing the camera view mostly from below for having a more imposing view of the buildings. For a fluent tracking shot, the camera follows objects in the foreground while moving around, e.g. the rope of a little crane or the handrails of a staircase, E) night scenes consisting of short shots for a similar atmosphere as for the introduction, F) closing credits showing the castle in the background. The motive of visualisation is picked up by the drawing of the scene in the foreground (Fig. 10). All scenes were created with the video editor in Lumion, within which all camera views were defined with snapshots of the scene. The software then smoothly interpolates between those frames to render each frame in between.

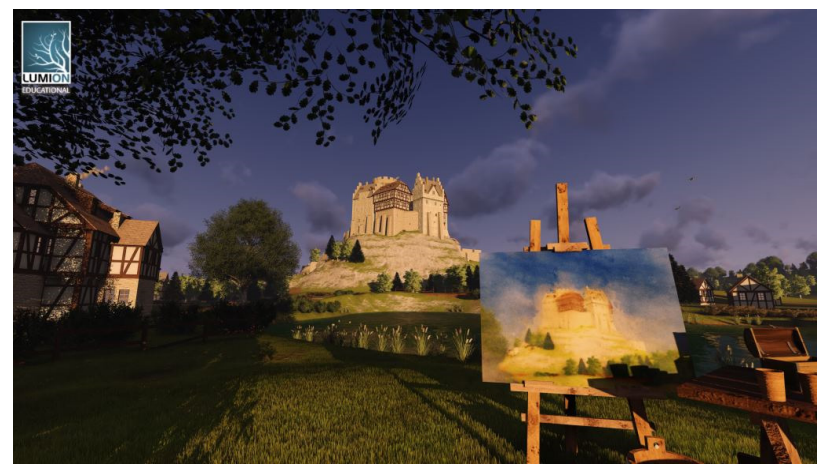

Figure 10. Drawing of the castle as shown in the closing credits of the video sequence

Visual Effects: The raw version of the video sequence of the 3D environment has been manipulated in the video editor to enhance the graphical quality of specific scenes. The video editor offers an effect library. Each effect can be applied for specific parts of the video and is variable in length and intensity. In total, this video used 17 different types of effects, the most important of which are described below:

A) Clouds and fog were used to create the impression of a long distance towards the border of the scene in order to hide the skyline, B) depth of field to blur objects very distant or very close to the camera resulting in a more realistic look. Incidentally, this effect can be used to guide the viewers' attention to a certain point in the video, C) titles for implementing writing of the opening titles and the closing credits, D) vignette effect for creating a soft black frame at the border of the image to restrict the field of view, letting the viewer focus on the shown part in the centre, E) editing of the position and intensity of the sun for simulating the course of the day, F) colour correction allowing the editing of the RGB-values of the images. This was used to apply a red shade to opening titles and the closing credits sequences to create the atmosphere of morning / evening, G) volume sunlight and lens flare effects for editing the sunlight at particular angles.

Both visual effects and animations are managed by placing markers on a timeline to specify fixed conditions between which the software interpolates. Fig. 11 shows an example of the changes in the same image, created by visual effects. 

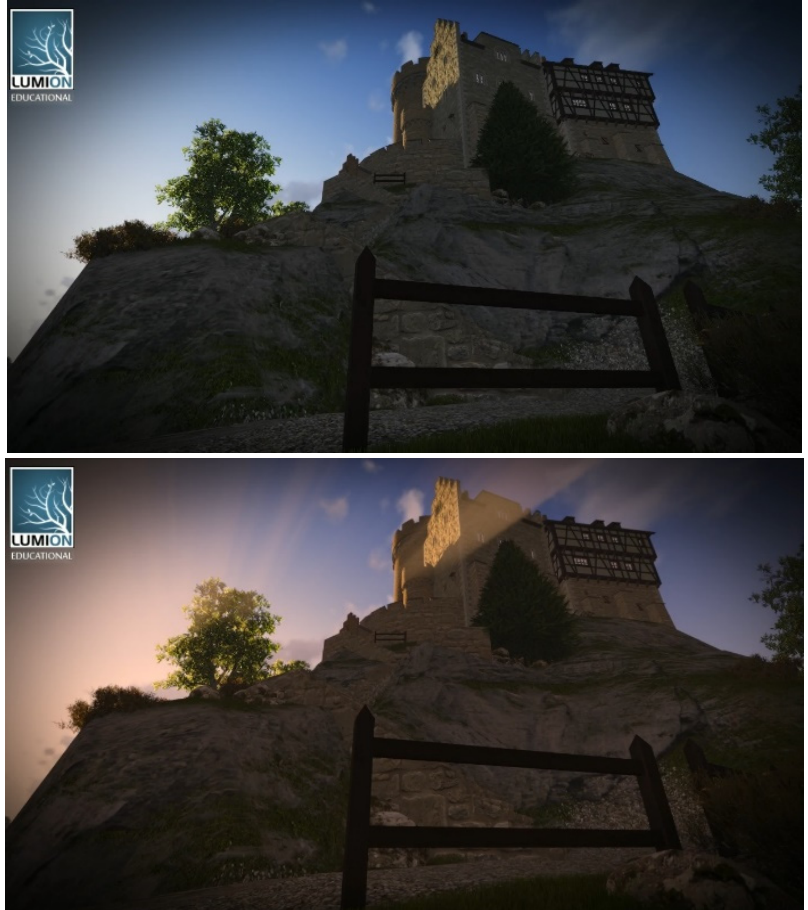

Figure 11. A frame of the opening sequence without (top) and with (bottom) volumetric sunlight and colour correction. Both images already have the vignette effect (borders fade to black)

Rendering: The rendering time depends on the following criteria: the number of effects, processing demands of these effects, length of the video sequence, frames per second (fps) rate, resolution and content of each frame. The video was rendered in $720 \mathrm{p}(1280 \times 720$ pixel $)$ using 30 frames per second. The generated video consists of 11370 frames, which corresponds to a length of $6.19 \mathrm{~min}$, resulting in a rendering time of about 36 hours. Additionally to the 2D version, a 3D video version was generated in Lumion. Therefore, the effect library provides an effect with stereoscopic options. With the specification of eye distance and focal length, the software renders two camera parts slightly next to the original one. Since there is only one calculation for lighting and shadows for the stereo images, the rendering time for the $3 \mathrm{D}$ version takes only eight hours longer than the 2D version providing MP4 file formats for both versions. Consequently, the $3 \mathrm{D}$ video version needs a 3D screen for correct display.

\subsection{Audio}

The background music of the video is a very important tool to influence the spirit of the video and to support or highlight certain elements. Since no appropriate, publically available soundtrack for this video could be found in the Internet, the music integrated in the video sequence was self-composed. This allowed for finetuning between audio and video, so that both media form a harmonic unit. Visual atmospheres are supported by a corresponding use of instruments, rhythms and sounds. Thus, camera path and movements and even individual cuts could be set in the appropriate musical theme.

\section{CONCLUSIONS \& OUTLOOK}

In this contribution the virtual 3D reconstruction of the destroyed and disappeared cultural heritage monument Siegesburg including the Kalkberg in Segeberg, Germany has been presented. Using isometric maps such the one from Braun-
Hogenberg, historic sources and expert knowledge, the castle and the appertaining Kalkberg were successfully reconstructed in 3D for the generation of video sequences in Lumion 3D representing a half-timbered architecture from Central Germany (Fig. 12), while a second video generated with 3ds Max represents the northern European Brick Gothic (Fig. 13). These video sequences symbolise the virtual return of the Siegesburg, while the physical return was already realised using the physical castle model in the museum exhibition. Furthermore, a 3D video has been generated using Lumion 3D.

The two final Lumion videos (2D/3D) have a length of $6: 19 \mathrm{~min}$ and a file size of ca. $700 \mathrm{Mb}(2 \mathrm{D})$ and ca. $950 \mathrm{Mb}(3 \mathrm{D})$ using the file format MP4. The 2D video version with the title "Siegesburg Segeberg 1588" is available for free viewing on the YouTube channel "HCUHamburgGeomatics" of the Hafencity University Hamburg under the following link: https://www.youtube.com/watch?v=M1pQnAhvQ4w.

Additionally, some single high-resolution still images were rendered for additional use in the museum exhibition (Fig 12).
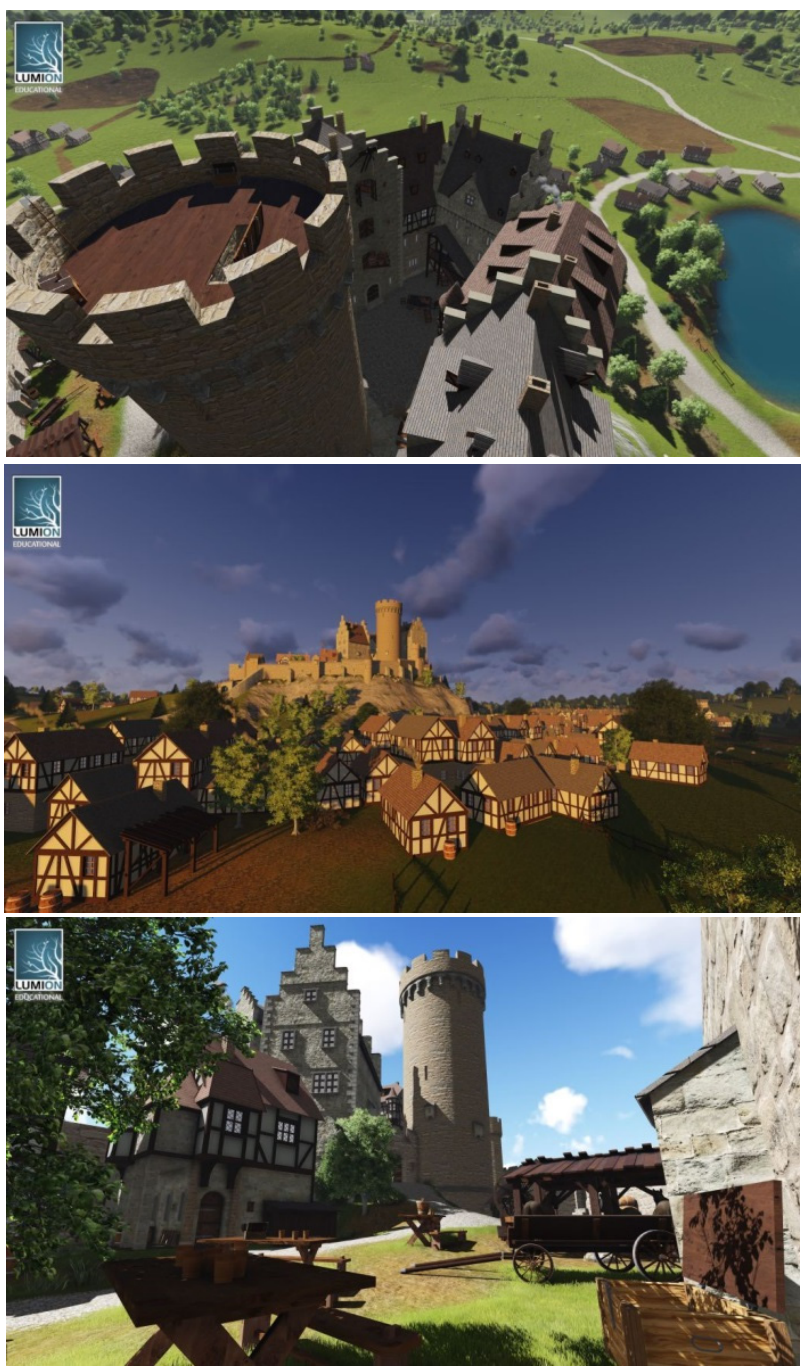

Figure 12. View from the castle keep (top), from the north (middle) and from the castle yard (bottom) generated with Lumion

As already mentioned, a second modelling and visualisation project ran in parallel using $3 \mathrm{ds}$ Max as visualisation software and focussing on a more realistic Brick Gothic Texture for the castle. The resulting video is also available for free viewing on 
the same YouTube channel under the following link: https://www.youtube.com/watch? $\mathrm{v}=\mathrm{V}-\mathrm{hESSCwOe} 0 . \quad$ The detailed description of the $3 \mathrm{D}$ reconstruction and visualisation of the Siegesburg using AutoCAD und 3ds Max is presented in Herzberg (2015). Two perspective views of the Siegesburg with Brick Gothic textures are illustrated in Fig. 13
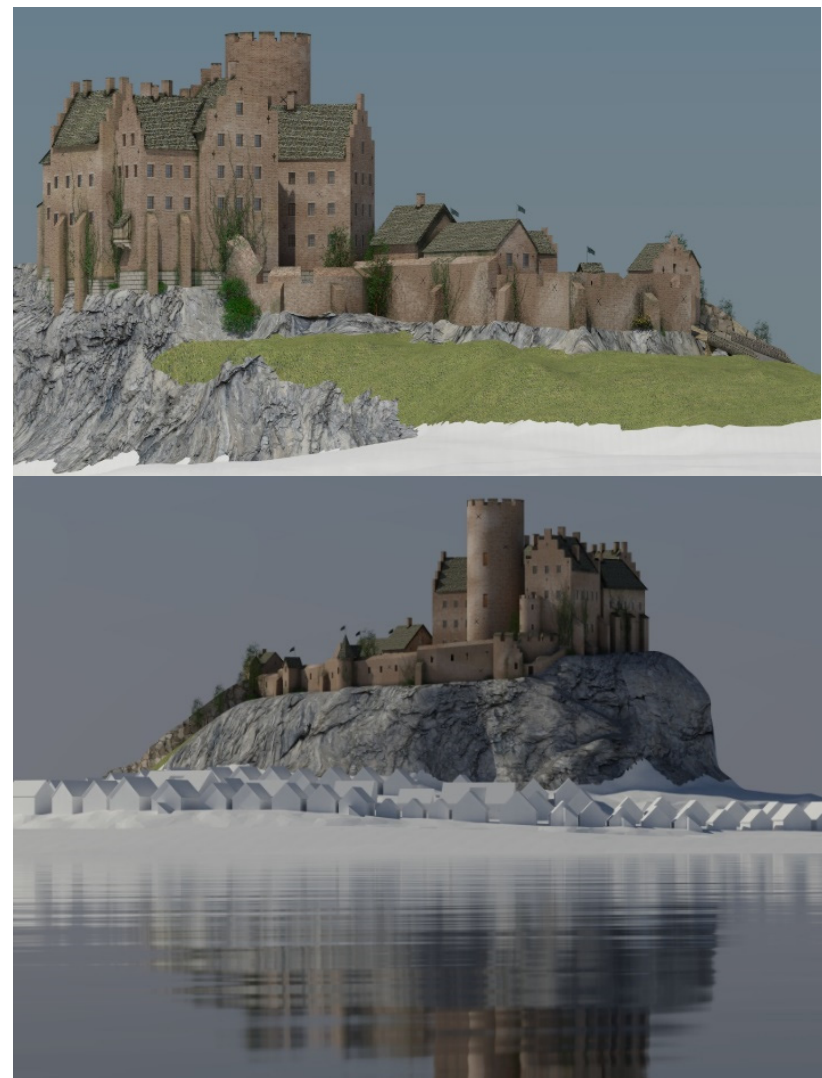

Figure 13. Two perspective views of the Siegesburg on top of the Kalkberg rendered with 3ds Max

The current follow-up project "Segeberg 1600" is about the historically correct reconstruction of the whole urban and rural area of the two villages Segeberg and Gieschenhagen in the year 1600. Some of the models of the Siegesburg will be reused as revised and improved versions for this project, especially concerning textures in the Brick Gothic and details. The idea of this project is the implementation of the entire 3D data of the village Segeberg in a game engine for a virtual reality application using the Virtual Reality System HTC Vive as it is already realised for the museum Alt-Segeberger Bürgerhaus (Kersten et al. 2017).

The 2D version of the history of the Siegesburg and the village is shown regularly in the exhibition of the museum Alt-Segeberger Bürgerhaus in Bad Segeberg, Germany. The combination of the physical model and the video helps the visitors to visualise the situation of Segeberg and especially the castle more than 400 years ago. Since the castle and the whole urban environment changed drastically since then, parts of the history of Segeberg are very little known in the common memory - up to the point that many people aren't aware that there once was a castle on top of the Kalkberg at all. This project helps to emphasise the historical awareness of the local community and the interested tourists in such historic events. This $3 \mathrm{D}$ reconstruction of a disappeared monument also demonstrates the potential in the documentation, visualisation and preservation of current or already destroyed cultural heritage objects.

\section{REFERENCES}

Deggim, S. 2015. Visualisierung der historischen Siegesburg in Bad Segeberg. Unpublished project report, Master study program Geomatics, HafenCity University Hamburg, 36 p.

Deggim, S. 2016. Entwicklung eines virtuellen Museums für ein historisches Gebäude am Beispiel des Alt-Segeberger Bürgerhauses. Unpublished Master thesis, Master study program Geomatics, HafenCity University Hamburg, 82 p.

Fangi, G. \& Wahbeh, W., 2013. The destroyed Minaret of the Umayyad Mosque of Aleppo, the Survey of the Original State. European Scientific Journal, SPECIAL edition, vol. 4, 403-409.

Grün, A., Remondino, F. \& Zhang, L., 2002. Reconstruction of the great Buddha of Bamiyan, Afghanistan. The International Archives of the Photogrammetry, Remote Sensing and Spatial Information Sciences, 34(5), 363-368.

Herzberg, A.-C., 2015. Visualisierung der Siegesburg von Bad Segeberg mit 3Ds Max Design. Unpublished project report, Master study program Geomatics, HafenCity University Hamburg, $28 \mathrm{p}$.

Kersten, Th., Acevedo Pardo, C. \& Lindstaedt, M., 2004. 3D Acquisition, Modelling and Visualization of north German Castles by Digital Architectural Photogrammetry. The International Archives of Photogrammetry, Remote Sensing and Spatial Information Sciences, 35 (B2), 126-132.

Kersten, T., Lindstaedt, M., 2012. Virtual Architectural 3D Model of the Imperial Cathedral (Kaiserdom) of Königslutter, Germany through Terrestrial Laser Scanning. EuroMed 2012 Int. Conference on Cultural Heritage, Ioannides, M.; Fritsch, D.; Leissner, J.; Davies, R.; Remondino, F.; Caffo, R. (Eds.), Lecture Notes in Computer Science (LNCS), Volume 7616, SpringerVerlag Berlin Heidelberg, 201-210.

Kersten, T., Hinrichsen, N., Lindstaedt, M., Weber, C., Schreyer, K. \& Tschirschwitz, F., 2014. Architectural Historical 4D Documentation of the Old-Segeberg Town House by Photogrammetry, Terrestrial Laser Scanning and Historical Analysis. Progress in Cultural Heritage. Documentation, Preservation, and Protection, 5th International Conference, EuroMed 2014, Limassol, Cyprus, November 3-8, 2014, Ioannides, M., Magnenat-Thalmann, N., Fink, E., Zarnic, R., Yen, A.-Y., Quak, E. (Eds.), Lecture Notes in Computer Science (LNCS), Volume 8740, Springer International Publishing Switzerland 2014, 35-47.

Kersten, T., Tschirschwitz, F. \& Deggim, S., 2017. Development of a Virtual Museum including a 4D Presentation of Building History in Virtual Reality. The International Archives of the Photogrammetry, Remote Sensing and Spatial Information Sciences, XLII-2/W3.

Meydenbauer, A., 1867. Ueber die Anwendung der Photographie zur Architektur- und Terrain-Aufnahme. Zeitschrift für Bauwesen, 17, 61-70.

Wahbeh, W., Nebiker, S. \& Fangi, G., 2016. Combining Public Domain and Professional Panoramic Imagery for the Accurate and Dense 3D Reconstruction of the Destroyed Bel Temple in Palmyra. ISPRS Annals of the Photogrammetry, Remote Sensing and Spatial Information Sciences, III-5, 81-88.

Wiedemann, A., Hemmleb, M. \& Albertz, J., 2000. Reconstruction of historical buildings based on images from the Meydenbauer archives. The International Archives of Photogrammetry and Remote Sensing, 33(B5/2; PART 5), 887893 